\title{
Frequency of Lympnode Metastasis in Supraglottic Ca Larynx
}

\author{
Mohammad Rokan Uddin Bhuiyan*1, Mohammad Idris Ali ${ }^{2}$, Balayet Hossain Siddiquee ${ }^{3}$, \\ Fatema Johora ${ }^{4}$, Mohammad Kamal Hossain ${ }^{5}$
}

\section{Abstract}

Introduction: To observe the association between the level of lymph node metastasis and the T-stage and to evaluate the $N$ - stage in supraglottic carcinoma of larynx. Materials and Methods: A prospective cross-sectional study was carried out on 80 consecutive cases of supraglottic carcinoma larynx in three tertiary level hospital in Dhaka during July'2009 to March 2011. Results: The highest number of patients were in the age group 5th and 6th decades. Male to female ratio was 9:1. Topographically 70 cases $(87.5 \%)$ had lesions involving epiglottis, 5 cases $(6.25 \%)$ in aryepiglottic fold and 5 cases $(6.25 \%)$ had lesions at false cord. Majority cases were histopathologically confirmed squamous cell carcinoma (95\%) and among them 46 cases (57.5\%) had well differentiated. Cervical metastatic lymph nodes were found $40 \%$ (32 cases) where level-II was most common. This was most frequent in early supraglottic(T1\&T2) carcinoma of larynx $(86.25 \%), P=0.008$. A positive correlation was found between the T stage of primary tumours and frequency of cervical lymphadenopathy. Lymph node metastasis were 4.77\% in T1, 37.50\% in T2, 71.43\% in T3 and $91.67 \%$ in T4. In early stage lymph node involved 93.75\% in Level- II, 6.25\% in Level- III \& in advanced stage 100\% in Level - II, 62.5\% in Level - III and 25.0\% in Level - IV. Distribution of study cases (31.25\%) in stage-II, 25\% in stage-I, 22.50\% in stage-Ill and $21.25 \%$ were in stage-IV. Conclusion: Result of this study may help the clinician for planning of treatment of this malignant diseases as well awareness.

Keywords: Supraglottic carcinoma, Neck node metastatic.

Number of Tables:06; Number of Figures:02; Number of References: 17; Number of Correspondences:05

*1. Corresponding Author:

Dr. Mohammad Rokan Uddin Bhuiyan

MBBS, FCPS, MS

Assistant Professor

Kurmitola General Hospital, Dhaka.

2. Dr. Mohammad Idris Ali

MBBS, MS

Consultant

Department of ENT

Bangabandhu Sheikh Mujib Medical University, Dhaka.

3. Prof. Balayet Hossain Siddiquee

Professor

Department of ENT

Bangabandhu Sheikh Mujib Medical University, Dhaka.

4. Dr. Fatema Johora

MBBS, MPhil, MMed

Associate Professor

Department of Anatomy

Sir Salimullah Medical College, Dhaka.

5. Lt Col Mohammad Kamal Hossain

Assistant Professor

Department of ENT

Arms Forces Medical College, Dhaka.

\section{Introduction}

The larynx is the most common site for primary malignant tumour in head and neck region $1,2,3$ which accounts for $25-30 \%$ of Head and neck malignancy. It represents $1-2 \%$ of all malignancy in men ${ }^{4}$. Which is the 11 th most common cancer in men worldwide ${ }^{5}$. There is a steady rise in the incidence of cancer of the larynx during the past decades ${ }^{6}$. A higher incidence of laryngeal carcinoma has been reported from Asian population. In the western Asia and India, laryngeal cancer account for more than $6 \%$ of all cancers among men.

Carcinoma larynx is not uncommon in Bangladesh. Laryngeal cancer is one of the 10 most common cancers in Bangladesh ${ }^{7}$. Study in our country showed that the number of patients suffering from carcinoma larynx is increasing gradually ${ }^{1,3}$. One study in this country had shown $35.32 \%$ of all cancer was in head and neck region and the commonest head and neck malignancy was laryngeal carcinoma $31.58 \%{ }^{3}$. In a recent study shows the overall incidence of Head and Neck Squamous cell carcinoma was 150 person in $1,00,000$ population $(0.15 \%)$. This study also revealed that incidence of carcinoma of the larynx was $25.22 \%$. Highest incidence was found in the 6 th decade of life in both sexes with male female ratio was $4.5: 1^{8}$.

One of the most important significant prognostic factors in head and neck cancer is the presence or absence, level and size of metastatic neck disease. A single ipsilateral cervical lymph node metastasis decreases 5- year survival rate by $50 \%$ patients with squamous cell carcinoma of the supraglottis of larynx. This survival rate decreases according to the number and level of the metastatic neck node involved and presence of capsular rupture ${ }^{9}$. Nodal metastasis is also associated with a high rate of regional recurrence ${ }^{10}$. This study tries to correlate the metastatic neck node in different stage of supraglottic carcinoma. In this study it has tried to find out significance of frequency of neck node metastasis in different stage of supraglottic laryngeal carcinoma. So far it is known, comparative study on this 
subject was not carried out previously in our country. The result of the study will provide some knowledge about the incidence and pattern of neck nodal metastasis of the supraglottic laryngeal carcinoma with their presentation and association factors, which may help in the early and appropriate diagnosis of the diseases and choice of treatment modalities.

\section{Materials and Methods}

This cross sectional study which was carried out in the department of otolaryngology-Head \& Neck Surgery BSMMU, DMCH, SSMC Hospital during this period of July 2009 to March 2011. A total 80 patients of supraglottic carcinoma admitted in the department of ENT Head-Neck Surgery, BSMMU, DMCH, \& Mitford Hospital during the study period. All the patients of supraglottic carcinoma admitted in the respective department diagnosed and confirmed by clinical examinations, endoscopic biopsy and histopathology. After taking informed consent and matching the inclusion criteria were included in this study. A Standardized structured data collection instrument was used to collect necessary information of the study subject, which includes-particulars of the patient, demographic profiles, History, clinical examination, laryngoscopic finding, cytological and histological findings, and relevant radiological findings.

Results \& Observations

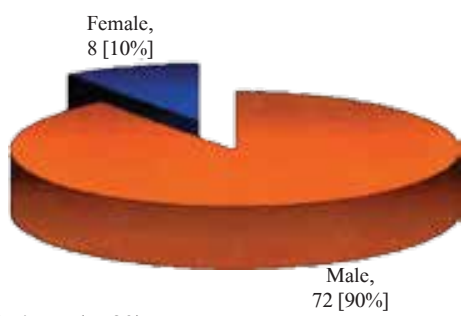

Figure-1: Sex distribution of the Patients $(\mathrm{n}=80)$.

Table-I: Age distribution $(\mathrm{n}=80)$.

\begin{tabular}{lcc}
\hline Age & No of Patients & Percentage (\%) \\
\hline $40-49$ Years & 16 & $20.0 \%$ \\
$50-59$ years & 38 & $47.5 \%$ \\
$60-69$ years & 20 & $25.0 \%$ \\
$70-79$ years & 4 & $5.0 \%$ \\
$80+$ years & 2 & $2.5 \%$ \\
\hline Total & 80 & $100.0 \%$ \\
\hline
\end{tabular}

Table-II: Site of involvement of growth supraglotticcarcinomalarynx $(n=80)$.

\begin{tabular}{lcc}
\hline Distribution of cases & No. of cases & Percentage \\
\hline Aryepiglottic folds and & & \\
Arytenoids with Epiglottis & 40 & $50.00 \%$ \\
Epiglottis with Vestibule & 19 & $23.75 \%$ \\
Epiglottis & 11 & $13.75 \%$ \\
False cord & 5 & $6.25 \%$ \\
Aryepiglottic folds & 5 & $6.25 \%$ \\
\hline
\end{tabular}

Table-III: Histological grading of carcinoma larynx $(n=80)$.

\begin{tabular}{lcll}
\hline Grading & Degree of differentiation & Number & Percentage \\
\hline I & Well differentiated & 46 & $57.50 \%$ \\
II & Moderately differentiated & 24 & $30.00 \%$ \\
III & Poorly differentiated & 06 & $7.50 \%$ \\
IV & Undifferentiated & 04 & $5.00 \%$ \\
\hline
\end{tabular}

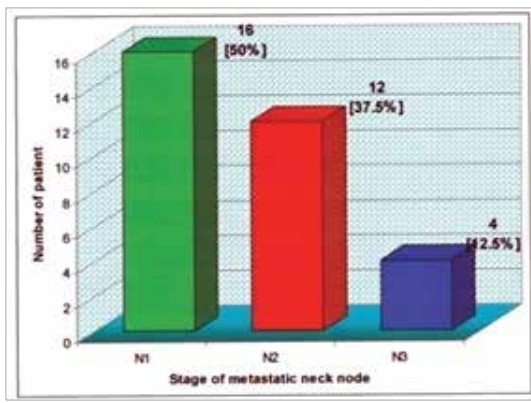

Figure-2: Stage [N] of metastatic neck nodes [ $n=32]$.

Table-IV: Distribution of Level of Neck node in different tumor stage $(\mathrm{n}=32)$.

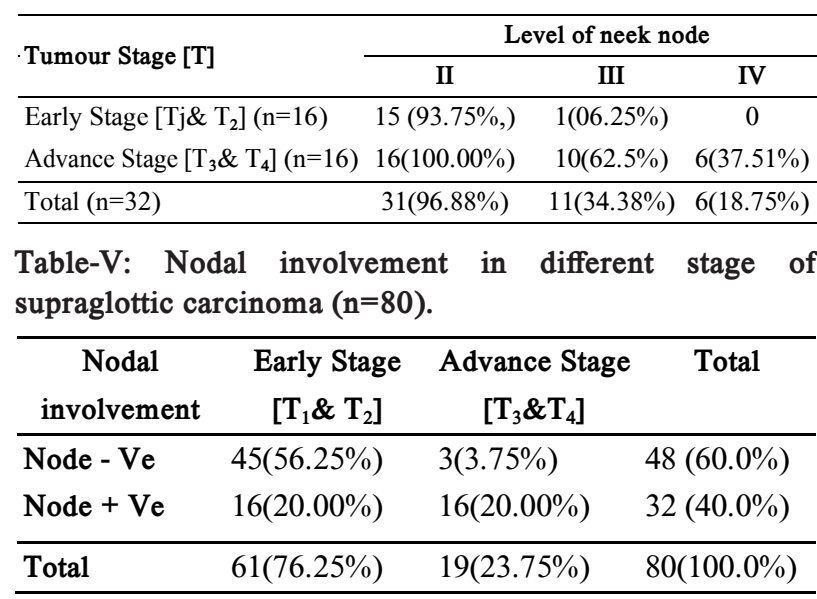

Table-VI: Staging [TNM] patient $\mathbf{n}=80$.

\begin{tabular}{lll}
\hline Stage [TNM] & Number of cases & Percentage \\
\hline Stage-I & 20 & $25.0 \%$ \\
Stage-I & 25 & $31.25 \%$ \\
Stage-Ill & 18 & $22.50 \%$ \\
Stage-IV & 17 & $21.25 \%$ \\
\hline
\end{tabular}

\section{Discussion}

Carcinoma larynx is not uncommon in Bangladesh. Laryngeal cancer is one of the 10 most common cancers in Bangladesh ${ }^{7}$. Previous study revealed that incidence of carcinoma of the larynx was $25.22 \%$. Highest incidence was found in the 6th decade of life in both sexes with male female ratio was $4.5: 1^{8}$. Supraglottic carcinoma of larynx is a common (67-73\%) disease in otolaryngology in Bangladesh ${ }^{11,12,13}$

80 patient of supraglottic carcinoma fulfilling the inclusion criteria were included in this cross sectional study from 
purposively selected three tertiary hospitals of Dhaka during July 2009 to March 2011. Among them 32 [40\%] patient had metastatic neck node.

The incidence (as opposed to mortality) of laryngeal carcinoma is common with other head and neck cancer increase with age. This is predominantly found in patient aged from 50-70 years ${ }^{14,15,16}$. In this study age of the patient ranged from 38-83 years (mean $57.58 \pm$ SD 9.79 years). $38(72.5 \%)$ of patients were in the 5th- 6 th decade. Highest number $(38,47.5 \%)$ of patient with supraglottis carcinoma larynx was found between 50 to 59 years of age. No case was found below 38 years of age. In the developing countries many cases are diagnosed in individuals before 5 th decade of live. Less than $1 \%$ of Carcinoma of the larynx occur before age of 30 except for the supraglottic type that has a lower age range ${ }^{5}$.

One invariable characteristic of carcinoma of the larynx is its greater predominance in men compared with women ${ }^{14}$. The male/female ratio ( $8: 1)$ is higher for cancer at any other site, thus emphasizing the rarity of laryngeal cancer among females ${ }^{11}$. This international male/female ratio for the incidence of laryngeal carcinoma Male to female ratio was (M:F) $9: 1^{4}$. The overall male to female ratio varies $4: 1$ to $20: 1$. Here $72(90 \%)$ patient were male and $8(10 \%)$ were female, Male to female ratio was 9:1, which was consistent with other studies in Bangladesh and in this subcontinent.

Most of the supraglottic growth was exophtic in appearance $(60 \%)$. 40\% lesion was ulcerative type. No fungating type was observed in this study. This two types had no statistically significant difference $(\mathrm{P}=0.127)$. This was also similar to study of Haque, 2000.

The most common site of origin of supraglottic carcinoma is the center of infrahyoid epiglottis followed by the false cord, suprahyoid epiglottis, aryepiglottic fold and ventricle $^{15}$. The common site of involvement of supraglottic carcinoma in this study was epiglottis $(87.5 \%) .5$ cases $(6.25 \%)$ were in Aryepiglottic fold and other 5 cases $(6.25 \%)$ had lesions at false cord. There was statistically significant difference among the involvement of carcinoma in other different sites of the supraglottic larynx $(\mathrm{P}<0.001)$.

In this study all the carcinoma larynx were found as squamous cell carcinoma of different variant and degree of differentiation. Majority of the subjects were found well-differentiated $(57.5 \%)$ which was belong to grade- I. $30 \%$ patients had moderately differentiated (grade- II) and $7.5 \%$ (grade- II) patients had poorly differentiated carcinoma (grade- III) and $4(5 \%)$ patients had undifferentiated carcinoma (grade- IV).

Out of 80 patient $32(40 \%)$ had their regional lymph nodes involved. There was not a significant difference in the proportions of individuals with the presence or absence of metastatic neck node $(\mathrm{z}=1.526, \mathrm{P}=0.127) .16(50 \%)$ patient were found in early stage of neck node metastasis $(<3 \mathrm{~cm}$ in size in ipsilateral side). Homolateral involvement of nodes were found in most cases 28 (87.5\%).

One of the most important significant prognostic factors in head and neck cancer is the presence or absence, level and size of metastatic neck disease. A single ipsilateral cervical lymph node metastasis decreases 5- year survival rate by $50 \%$ patients with squamus cell carcinoma of the supraglottis of larynx. This survival rate decreases according to the number and level of the metastatic neck node involved and presence of capsular rupture ${ }^{9}$. Nodal metastasis is also associated with a high rate of regional recurrence ${ }^{10}$.

Poorly differentiated tumours have the highest of distance metastasis. Though presented late, in no case of our series distant metastasis was found. So, all were in M0 state. In presentation staging was concerned maximum $(31.25 \%)$ at stage-II followed by $22.50 \%$ at stage-III, $25 \%$ in stage-I and $21.25 \%$ were in stage-IV. (Table-II). The distributing of stage is almost nearer to others studies ${ }^{11,12,17}$. For proper staging CT Scan and MRI were necessary, but could not done for monetary problem of the patients.

\section{Conclusion}

To evaluate the cervical lymph node metastasis in different stage of supraglottic laryngeal carcinoma this cross sectional study was done in limited three hospitals in Dhaka among limited number of subjects. Lymph node metastasis was found in early supraglottic carcinoma (T1\& T2) of larynx is significantly frequent in level II cervical lymph node. There was also significant association and correlation was found in advance stage of tumour with the size of tumour and node, site of involvement, age and sex groups, smoking and sociodemographicfactors. Result of this study may help the clinician for their planning of treatment of this malignant diseases as well prevention.

\section{Conflict of Interests: None.}

\section{Acknowledgement}

This study was conducted at the department of otolaryngology\& head-neck surgery Bangabandhu Sheikh Mujib Medical University under the guidance of Prof. Belayat Hossain Siddiquee chief of head - neck surgery division, department of otolaryngology \& head - neck surgery, BSMMU with help of other authors as a thesis of the corresponding author.

\section{References}

1. Haque S F. Cancer incidence in Bangladesh. Journal of Bangladesh College of Physician \& Surgeons.1987(Aug); 5(1): 1-7.

2. Chakraborty, S, Kar, TK, Ghosh, LM. Neoplasm of Ear, Nose and Throat. Indian Journal of Otolaryngology \& Head and Neck Surgery.1992;1(3): 113-18. 
3. Alauddin M, Ahmed K, Chowdhury A M, Sarkar MRI.Head and Neck Cancer-a study of 4215 cases. Bangladesh Journal of Otolaryngology and Head and Neck surgery. 1997; 3(2): 39-41.

4. Makitie A, Pukender J, Raitiola H, Hyrynkangas K K, Virtaniemi J, Grenman R. Changing trends in the occurance and subsite distribution of laryngeal cancer in Finland. European Archives of Otolaryngology.1999.

https://doi.org/10.1007/s004050050245

5. Parkin, DM, Whelan, SL, Ferlay, J, et al. Cancer incidence in five continents.2002, Vol. VIII. Lyon: IARC, (IARC Scientific Publications No. 155).

6. Shah JP. Patterns of cervical lymph node metastasis from squamous carcinomas of the upper aerodigestive tract. Am J Surg. 1990 ; 160:405

https://doi.org/10.1016/S0002-9610(05)80554-9

7. Rashid, KM, Rahman, M,Hyder, S, et al.Hyder's Textbook of Community Medicine and Public Health.4th edition. 2007: 289.

8. SiddiqueeBH, Alauddin, M, Chowdhury, AA, Akhtar, et al. Head and Neck Squamous Cell Carcinoma (HNSCC) 5 years study at BSMMU, Bangladesh Med. Res. Counc. Bull. 2006; 32(2): 43-48.

9. Moe K, wolf GT, Fisher SG, Hong WK. Regional metastasis in patients in advanced laryngeal cancer. Chin Med J.2001; 115(1): 78-80.

10. Ogura JH. Surgical salvage in cancer of larynx. J. Bangladesh CollPhy Surg. 1992; 10:69-73.
11. Haque MR, Abdullah M, Alauddin M, Haroon AA, Majed MA, Ali MS. Carcinoma larynx- Topographical distribution. Mymensing Med J. 2002Jan; 11 (1): 15-21.

12. Amin, MN, Datta, P.G, Amin, A.S.A, et al. Clinical presentation of carcinoma larynx, Journal of Bangladesh College of Physician \& Surgeons. 1991; 8(2): 10-16.

13. Rahman SH, Alauddin M, Ahmed KU, Haroon AA, Ahmed SU. Staging pattern of laryngeal carcinoma - a study of 211 cases. Bangladesh Journal of Otolaryngology. 2002; 8(1): 19-23.

14. Rubin, P, Bakemeier, RF Krackov, SK. Clinical Oncology. A multidisciplinary approach. American Cancer Society Head and Neck Tumors. 6th ed. 1983; 19:230-261.

15. WalkinsonJ C, Gaze M N, Wilson J A.Tumours of the larynx. Stell and Maran's, Head and Neck Surgery. 4th ed.Butlerworth Heinemann, Oxford; 2000, 15: 233-273.

16. Birchall M A, Pope L. Tumours of the Larynx. Scott Brown's Otolaryngology \& Head-Neck Surgery; 2008; edited Michael Gleeson. 7th ed. Vol-2, part-17 Head and Neck Tumours, edited John Hibbert. Hodder Arnold Butlerworth Heinemann, Oxford. 2008, 194: 2598-2622.

https://doi.org/10.1201/b15118-213

17. Bhowmik. B, Huq, AHMZ, Talukdar, DC,Mondol, et al. Incidence of regional metastasis of supraglottic carcinoma larynx. Bangladesh Journal of Otolaryngology. 2007; 13(2): 37-42. 